\title{
End-Permian to mid-Triassic termination of the accretionary processes of the southern Altaids: implications for the geodynamic evolution, Phanerozoic continental growth, and metallogeny of Central Asia
}

\author{
W. J. Xiao $\cdot$ B. F. Windley $\cdot$ B. C. Huang $\cdot$ \\ C. M. Han · C. Yuan · H. L. Chen · \\ M. Sun $\cdot$ S. Sun $\cdot$ J. L. Li \\ Published online: 13 February 2009 \\ (c) Springer-Verlag 2009

\section{Erratum to: Int J Earth Sci (Geol Rundsch) \\ DOI 10.1007/s00531-008-0407-z}

The original version of this article unfortunately contained several mistakes in Figs. 8 and 9:

"Van der Voo et al. 1998" should be "Van der Voo 1993", "Kravchink et al. 1998" should be "Kravchinsky et al. 2002", "Huang et al. 2007" should be "Huang et al. 2008 ".

The references "Huang et al. 2005, 2007" in caption of Figs. 8 and 9 should be "Huang et al. 2005, 2008".

The corrected Figs. 8 and 9 and the Huang et al. references are given below:

The online version of the original article can be found under doi:10.1007/s00531-008-0407-z.

W. J. Xiao $(\varangle)$ · B. C. Huang · C. M. Han · S. Sun · J. L. Li State Key Laboratory of Lithospheric Evolution, Institute of Geology and Geophysics,

Chinese Academy of Sciences, 100029 Beijing, China

e-mail:wj-xiao@mail.igcas.ac.cn

\section{B. F. Windley}

Department of Geology, University of Leicester,

Leicester LE1 7RH, UK

C. Yuan

Guangzhou Institute of Geochemistry,

Chinese Academy of Sciences, 510640 Guangzhou, China

H. L. Chen

School of Earth Sciences, Zhejiang University,

310027 Hangzhou, China

M. Sun

Department of Earth Sciences,

The University of Hong Kong, Hong Kong, China

\section{References}

Huang BC, Xu B, Zhang CX, Li YA, Zhu RX (2005) Paleomagnetism of the Beiyixi volcanic rocks (ca. $740 \mathrm{Ma}$ ) of Tarim, Northwest China: a continental fragment of Neoproterozoic Western Australia? Precambrian Res 142(3-4):83-92

Huang BC, Zhou YX, Zhu RX (2008) Discussions on Phanerozoic evolution and formation of continental China, based on paleomagnetic studies. Earth Sci Frontiers 15(3):348-359 
Fig. 8 Paleomagnetic data for Siberia, South Kazakhstan, and Tarim cratons (modified after Van der Voo 1993; Van der Voo et al. 2006; Fang et al. 1996; Smethurst et al. 1998; Kravchinsky et al. 2002; Bazhenov et al. 2003; Huang et al. 2005, 2008). Star for Tarim, circle for Southern Kazakhstan, and diamond, open and solid box for Siberia from various references indicated

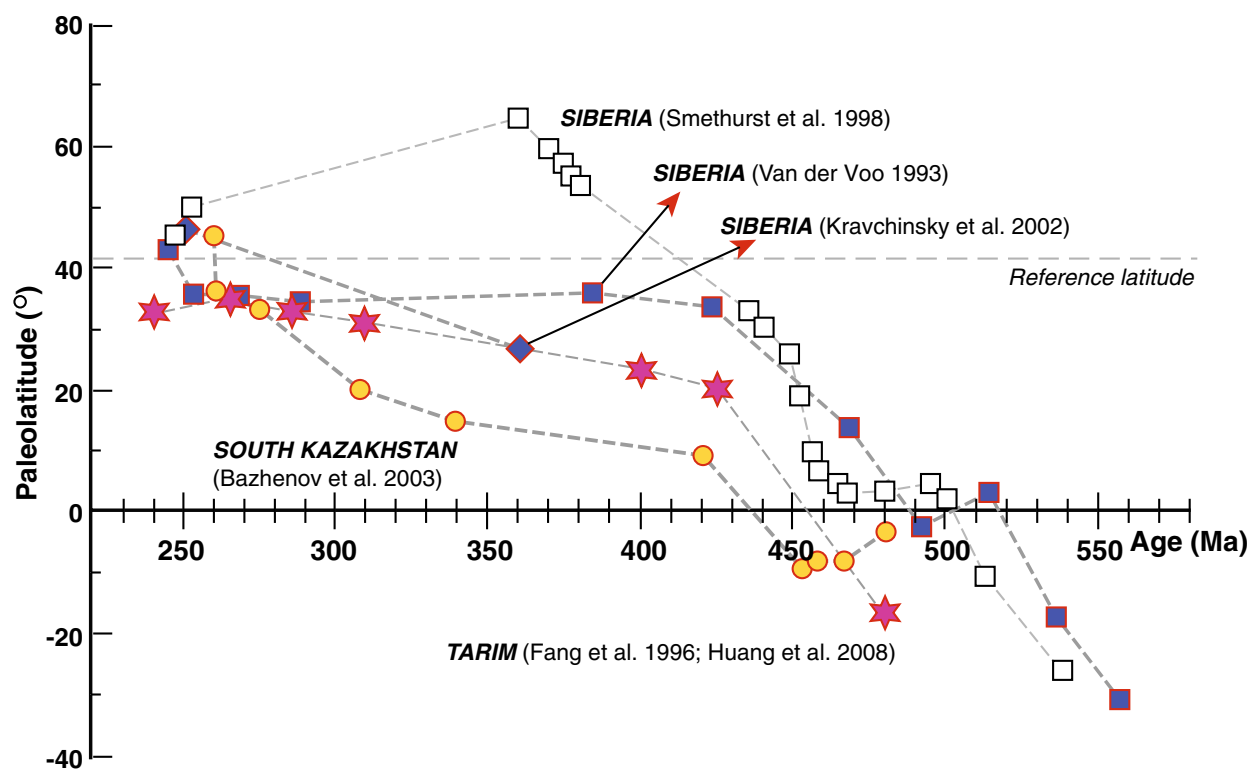

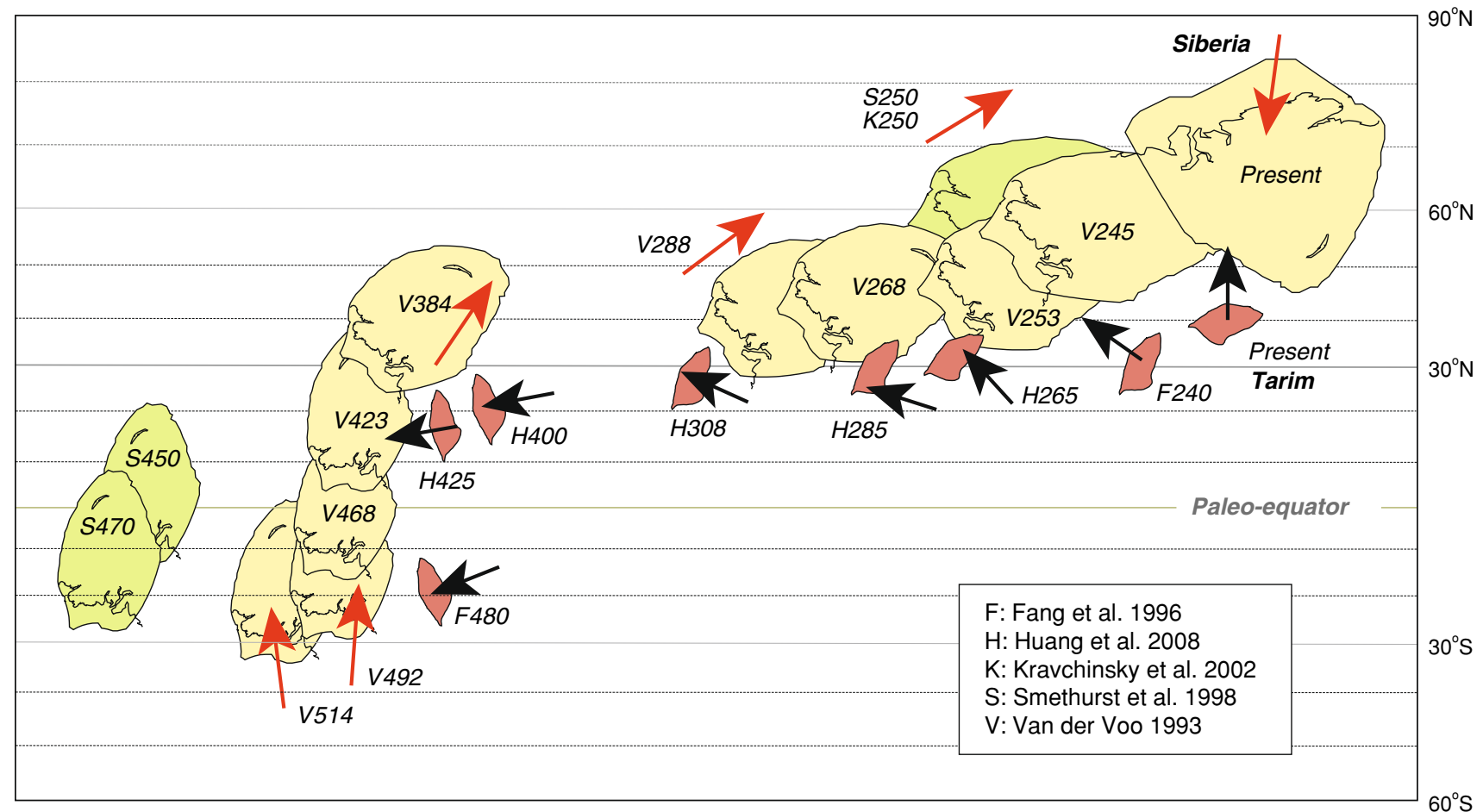

Fig. 9 Paleo-positions for Siberia and Tarim implied by APW paths and some key paleomagnetic poles for the two continents (Modified after Van der Voo 1993; Van der Voo et al. 2006; Fang et al. 1996; Smethurst et al. 1998; Kravchinsky et al. 2002; Bazhenov et al. 2003; Huang et al. 2005, 2008). Red arrows denote the present south pole of
Siberia, black bold arrows represent the present north pole of Tarim. Note that the relative position of the two continents does not represent the paleopalinspastic reconstruction. The green and yellow colors for Siberia from various references indicated 